\title{
Autoria em Blog por Pessoas em Sofrimento Psíquico: Aprendizagem Compartilhada, Reconhecimento e Promoção da Saúde Mental
}

Authorship In Blogs For People In Psychological Distress: Shared Learning, Recognition And Promotion Of Mental Health

Autoría En Blog Por Personas En Sufrimiento Psíquico: Aprendizaje Compartido, Reconocimiento Y Promoción De La Salud Mental

Ivanise Gomes de Souza Bittencourt, Deise Juliana Francisco

\& Luís Paulo Leopoldo Mercado

Universidade Federal de Alagoas

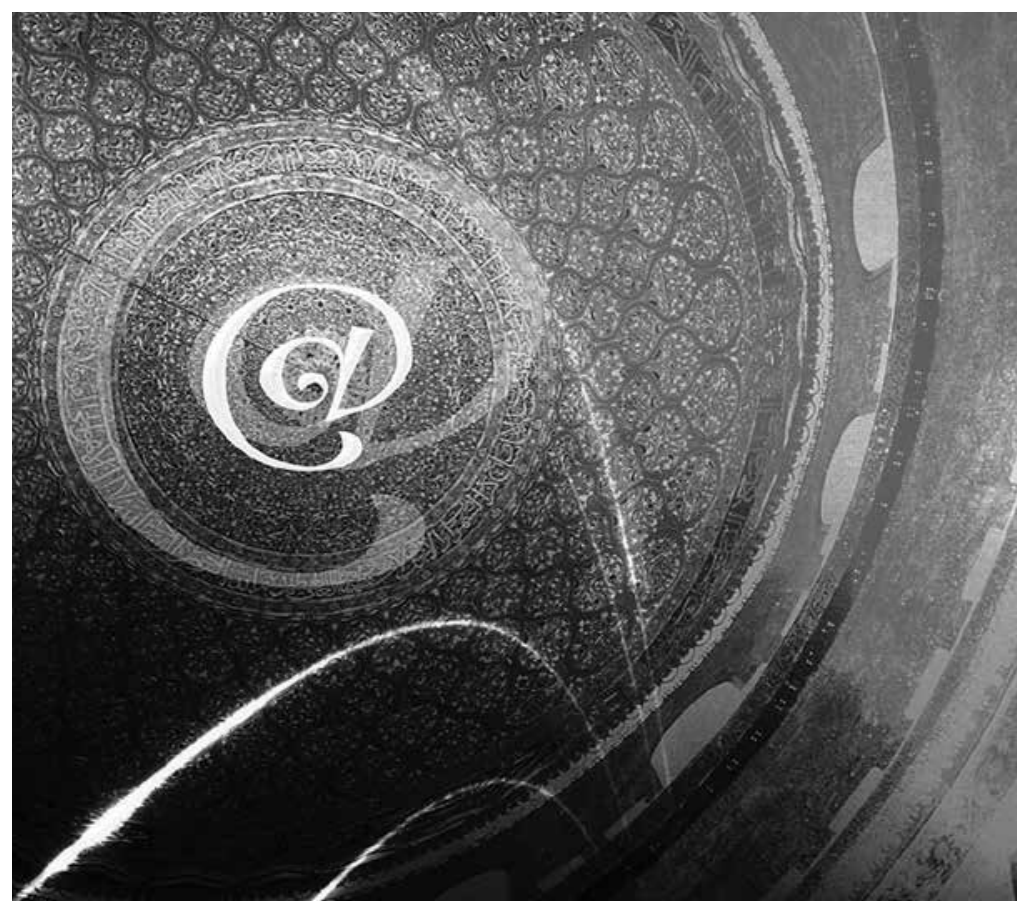


Resumo: O presente artigo discute a potencialidade de oficinas de informática na saúde mental. Inserido na reforma psiquiátrica, a proposta envolve o uso das tecnologias da informação e comunicação (TIC) no campo da saúde mental ao possibilitar às pessoas em sofrimento psíquico divulgar suas produções, trabalhar as suas capacidades e possibilitar a produção em autoria através da apropriação das diversas ferramentas da web. Empiricamente, traz uma experiência de oficina de informática realizada em um Centro de Atenção Psicossocial (CAPS) do Município de Maceió-AL, quando foram realizadas 12 oficinas de blog. Estas foram desenvolvidas com quatro usuários, com idades entre 21 e 34 anos. Este estudo é de caráter qualitativo e envolveu uma pesquisa-intervenção, na perspectiva de construção de novos modos de fazer em saúde mental e de uso das TIC. Para a coleta dos dados, foram utilizadas a observação participante, a criação de diário de campo e entrevistas semi-estruturadas, com temas que versavam sobre os efeitos da participação nas oficinas e na produção de materiais. Verificou-se que o blog constituiu um espaço de expressão, aprendizagem compartilhada, troca de experiências, reconhecimento e promoção da saúde mental.

Palavras-chave: Sofrimento. Saúde mental. Programas de saúde mental. Promoção da sáude.

\begin{abstract}
This article discusses the potential of computer workshops on mental health. Inserted in the psychiatric reform, the proposal involves the use of information and communication technologies (ICT) in the field of mental health to enable people in psychological distress to disseminate their productions, reinforce their capabilities and enable the production authorship through the appropriation of the various web tools. Empirically it brings an experience of computer workshop held in a Psychosocial Care Center (CAPS) in Maceió-AL, when 12 blog workshops were held. These were developed with four users, aged between 21 and 34 years. This study is qualitative in nature and involved a research intervention, the prospect of building new ways of dealing with mental health and the use of ICT. For data collection, participant observation, a field diary and semi-structured interviews were used, dealing with topics on the effects of the participation in workshops and production of materials. It was found that blogging became an expression space, shared learning, exchange of experiences, and recognition and promotion of mental health.
\end{abstract}

Keywords: Suffering. Mental health. Mental health program. Health promotion.

Resumen: El presente artículo discute la potencialidad de oficinas de informática en la salud mental. Inserto en la reforma psiquiátrica, la propuesta involucra las tecnologías de la información y comunicación (TIC) en el campo de la salud mental al posibilitarles a las personas en sufrimiento psíquico divulgar sus producciones, trabajar sus capacidades y posibilitar la producción en autoría a través de la apropiación de las diversas herramientas de la Web. Empíricamente, trae una experiencia de oficina de informática realizada en un Centro de Atención Psicosocial (CAPS) del Municipio de Maceió-Al, cuando fueron realizados 12 talleres de blog. Éstos fueron desarrollados con cuatro usuarios, con edades entre 21 y 34 años. Este estudio es de carácter cualitativo e involucró una investigación intervención, en la perspectiva de construcción de nuevos modos de hacer en salud mental y de uso de las TIC. Para la recolección de los datos, fueron utilizadas la observación participante, la creación de diario de campo y entrevistas semiestructuradas, con temas que versaban sobre los efectos de la participación en los talleres y en la producción de materiales. Se verificó que el blog constituyó un espacio de expresión, aprendizaje compartido, intercambio de experiencias, reconocimiento y promoción de la salud mental.

Palabras clave: Sufrimiento. Salud mental. Programas de la salud mental. Promoción de la salud.

A existência do sofrimento, para Amarante (2008), remete às experiências de um sujeito que sofre com os problemas do cotidiano no seu trabalho, em projetos e na relação familiar. Há profissionais que têm procurado trabalhar com tal problemática, na perspectiva da cidadania e na criação de um novo local social para essas pessoas, através da criação de dispositivos de atenção à saúde mental.

Nesse direcionamento, a atual Política Nacional de Saúde Mental, fundamentada nos ideais de uma sociedade humana e equânime, busca a reinserção social dos excluídos por sofrimento psíquico, lutando por uma sociedade livre de discriminação, preconceito e opressão. Uma das alternativas de intervenção compreende oficinas terapêuticas desenvolvidas nos serviços de saúde mental. Estas têm sido recriadas incorporando a utilização e a apropriação das tecnologias de comunicação e informação (TIC) em suas atividades, tanto como um meio de inclusão digital quanto como possibilitadoras da promoção da saúde 
mental. Algumas dessas iniciativas (Arza, 2011; Santos \& Melo, 2010; Capella Maraschin, Maurente, \& Rickes, 2008; Francisco, 2007) têm demonstrado resultados promissores e contribuições significativas na atenção, no tratamento e na promoção da qualidade de vida dos sujeitos que enfrentam o sofrimento psíquico.

A inclusão digital é tida por Michelazzo (2003) como a produção de materiais pelos cidadãos a partir da reflexão sobre seu contexto de vida. Tal processo viabiliza a disseminação da informática, a partir da redução de custos e da criação de um senso de comunidade, na medida em que o sujeito é instigado a participar de uma proposta de trabalho que precisa de sua ação para acontecer. Inclusão digital envolve disponibilização de computadores para classes populares, mas essa é apenas a infraestrutura necessária para a garantia de acesso, de produção, de seleção e de significado da informação.

Nesse sentido, trata-se do uso coletivo e significativo das TIC. Elas emergem como recursos tecnológicos e computacionais na sociedade em rede. Nas palavras do sociólogo espanhol, as tecnologias da informação tratam do "conjunto convergente de tecnologias em microeletrônica, computação (software e hardware), telecomunicações/radiodifusão, e optoeletrônica (...) a engenharia genética e seu crescente conjunto de desenvolvimentos e aplicações" (Castells, 2000, p. 49). Tais tecnologias concentram-se na decodificação, manipulação e reprogramação de códigos de informação.

A partir da perspectiva de Lévy (1993), entendemos as tecnologias da inteligência como composições de humanos e não humanos, em um híbrido de agentes coletivos, em que não há prévia determinação dos efeitos das tecnologias. Conforme Sibilia,
Existem agenciamentos coletivos, usos e apropriações das tecnologias por parte dos sujeitos que, por sua vez, também vivenciam seus efeitos em seus próprios corpos e subjetividades. Os aparelhos e ferramentas exprimem as formas sociais que os produzem e lhes dão sentido, formando redes, teias de pensamento, matrizes sociais, econômicas, políticas, que permeiam o corpo social inteiro e estão inextricavelmente ligados às novas tecnologias. (2002, p. 11)

Nessa perspectiva, Sales (2010) analisa que as tecnologias digitais operam como possibilitadores da solidificação de uma rede social de construção do conhecimento, na medida em que auxiliam os sujeitos no fortalecimento da autonomia, da autoria e da aprendizagem significativa, possibilitadoras e potencializadoras (Marcon, Teixeira, \& Trentin, 2009), e não operadores exclusivos, pois os sentidos são produzidos pelos sujeitos envolvidos.

Teixeira alerta para a necessidade de (re) significação da inclusão digital “(...) que tenha como base e finalidade a construção e a vivência de uma cultura de rede como elemento fundamental para o exercício da cidadania (...) diante de uma sociedade globalizada e conectada" (2010, p. 41). Para Foresti e Teixeira, a inclusão digital leva à formação de cidadãos responsáveis "que reconheçam suas potencialidades e responsabilidades, se apropriando de forma criativa e diferenciada das tecnologias de rede, libertando o ser humano de uma posição passiva" (2006, p. 6).

Partilhando dessa perspectiva, o presente estudo aponta algumas potencialidades das TIC para o campo da saúde mental e pretende contribuir com reflexões que possam fazer compreender como o exercício de autoria em blog pode ser relevante para a aprendizagem, o reconhecimento e a promoção da saúde mental para pessoas em sofrimento psíquico. 
Nas palavras de Domingues e Paravidini, "ainda que exista uma profusão de dificuldades,

o trabalho nas oficinas que operam uma coletividade cria tanto um produto quanto o sujeito que é produzido dentro desse operar" (2009,

s.p.).

\section{Oficinas de TIC em saúde mental}

As oficinas permanecem como importante dispositivo no processo de reforma psiquiátrica no Brasil, na medida em que se constituíram em eixos da política de saúde mental para além dos muros psiquiátricos, como estratégia de reabilitação psicossocial (Guerra, 2004). A prática das oficinas em saúde mental está prevista na legislação, como, por exemplo, na Lei de Saúde Mental no 10.216/2001, que propõe que diversos trabalhadores de saúde mental podem operar com oficinas diversas, tais como: oficina terapêutica e oficina de aprendizagem. A legislação, porém, aborda uma atividade e deixa em aberto a construção conceitual nos serviços substitutivos.

Domingues e Paravidini, em pesquisa na qual foram ouvidos usuários e profissionais de CAPS sobre oficinas, revelam que os depoimentos se referem a oficina de diversas formas, tais como: "um lugar de simbolização e de elaboração, de trocas e de socialização, de ocupação do tempo e da mesmice, de distração, de aprendizado e como um lugar possível de desconstrução do sujeito" (2009, s.p.). Sendo assim, na perspectiva de quem produz as oficinas, algumas vezes elas podem ter o caráter de ocupação do tempo.

A perspectiva da oficina como espaço clínicopolítico é partilhado por outros autores, como Mendonça: "As oficinas procuram caminhar no sentido de permitir ao sujeito estabelecer laços de cuidado consigo mesmo, de trabalho e de afetividade com os outros, determinando a finalidade político-social associada à clínica" (2005, p. 628).

Então, as oficinas têm se utilizado de diversas tecnologias, sendo mais contemporâneo o uso de tecnologias digitais. Capella et al., inclusive, apontam que os estudos que tratam das tecnologias digitais como ferramentas de intervenção ainda são incipientes, sendo necessários mais estudos para subsidiar reflexões ético-políticas sobre tal uso.

Nas palavras de Domingues e Paravidini, "ainda que exista uma profusão de dificuldades, o trabalho nas oficinas que operam uma coletividade cria tanto um produto quanto o sujeito que é produzido dentro desse operar" (2009, s.p.).

Oficinas de informática (Francisco, 2007), oficina de vídeo (...) e oficinas de rádio (...) já mostram trabalhos desenvolvidos na perspectiva da ética e do operar que envolve pesquisa. Em algumas, a pesquisaintervenção tem sido privilegiada como operador de relação entre a universidade e os serviços de saúde mental, em uma perspectiva participativa.

\section{Oficinas de blog e sofrimento psíquico}

Souza e Corrêa (2008) consideram os blogs como o maior fenômeno dos últimos anos, pois esses multiplicam-se a cada dia, disseminando-se entre todas as categorias de internautas, e inovam muito, entre os produtos comunicacionais, no aspecto da mediação.

Os tipos de blog são diversos, e incluem blogs jornalísticos, literários e pessoais, sendo que todos têm a mesma estrutura, ou seja, a de "um website que contém um diário pessoal com reflexões, comentários e também hyperlinks indicados por seu autor", conforme definição do dicionário online Merriam-Webster (http://www.merriamwebster.com).

O blog, conforme Capella et al., é um espaço de escritas e de imagens que possibilita uma ampliação das modalidades de comunicação e um registro em suporte digital, e pode ser escrito, de acordo com Orihuela (2007), 
pelo prazer de compartilhar informações ou como veículo de expressão. Ainda segundo esse autor, algumas razões que levam as pessoas a escrever blogs são a necessidade de expressão, o desejo de compartilhar saberes, o desejo de se integrar em uma comunidade, a busca de reconhecimento, a exploração criativa e como terapia. Segundo Souza, Silva e Araújo (2011), o blog é uma das ferramentas mais populares, e contribui para o desenvolvimento de habilidades de autoria, favorecendo a crítica, a autocrítica e a participação.

É possível também desencadear novos processos de desenvolvimento sociocognitivo para a diversidade humana, como afirmam Santarosa, Conforto e Basso (2010). Ainda segundo esses autores, o blog é um espaço para autoria individual e coletiva, e também de socialização das construções dos sujeitos, em que a própria inserção de comentários permite instituir uma prática de comunicação social. Orihuela destaca que “(...) a grande maioria dos blogueiros é composta por pessoas que escrevem sobre o que sabem, o que gostam, o que lêem (...)" (2007, ' p. 7), e essa linguagem funciona tanto como terapia quanto como identidade para a formação de vínculos sociais, conforme o autor.

\section{Desdobramentos metodológicos}

Este estudo é de caráter qualitativo, e envolveu uma pesquisa-intervenção realizada em um Centro de Atenção Psicossocial (CAPS) localizado no Município de MaceióAL. Trata-se de um CAPS II que conta com 41 trabalhadores de saúde mental (entre níveis superior, médio e fundamental), e assiste usuários a partir de 18 anos. As ações de atenção são variadas e correspondem a atendimento médico, psicológico, oficinas e a outras atividades coordenadas pelos trabalhadores, propostas de acordo com os objetivos de cada profissional com relação aos usuários cadastrados.
A pesquisa ${ }^{1}$ foi realizada mediante o contato direto com quatro usuários, sendo um do sexo feminino e três do sexo masculino, com idades entre 21 e 34 anos. Tal número foi limitado à quantidade de computadores disponíveis para a realização da pesquisa, sendo que a constituição dos grupos foi de livre vontade, tendo os participantes sido indicados pela equipe do CAPS e consultados sobre sua vontade de participar ou não da oficina. Da mesma forma, foram consultados os responsáveis pelos usuários sobre a atividade de pesquisa. Tais procedimentos foram importantes por duas razões: para constituir um trabalho coletivo e para respeitar os preceitos éticos de pesquisa com pessoas em sofrimento psíquico estabelecidos na Resolução no 196/96. Assim, os sujeitos e seus representantes legais assinaram o Termo de Consentimento Livre e Esclarecido (TCLE) e o Termo de Cessão de Direitos de Uso e Divulgação referentes à autorização para publicar as produções no blog.

Buscando uma interlocução da universidade com o estabelecimento de saúde, contamos com a participação de um membro da equipe do CAPS representado por uma das assistentes sociais do referido serviço. A perspectiva fora a de dar continuidade ao projeto, quando a universidade se ausentasse, ao final da pesquisa. $\mathrm{O}$ intuito foi, portanto, o de acompanhar o desenvolvimento dos usuários e de identificar as possibilidades e as contribuições de oficinas terapêuticas informatizadas ao serviço e usuários. Dessa forma, participaram da oficina usuários, trabalhadora de saúde, graduandos em Psicologia e Pedagogia e a pesquisadora proponente desta pesquisa.

No período de agosto a dezembro de 2011, foram realizadas 12 oficinas de blog. Com frequência semanal, os grupos foram coordenados pela pesquisadora deste estudo, o que possibilitou a interação e o uso das tecnologias digitais, com fins de reabilitação psicossocial. 
As oficinas terapêuticas informatizadas proporcionaram momentos de interação com o computador e de criação de atividades para o blog. Os recursos computacionais foram utilizados e procurados na medida em que iam sendo solicitados pelas atividades estabelecidas com os usuários no grupo.

Para a coleta dos dados, foram utilizados os prontuários dos participantes, a observação participante, a criação de diário de campo e entrevista semiestruturada. Os prontuários foram analisados com a intenção de coletar informações quanto aos seus históricos de condutas e particularidades antecedentes ao acompanhamento no CAPS. A observação participante constituiu-se do olhar da pesquisadora proponente dessa pesquisa durante todo o processo e das instruções quanto ao manuseio dos recursos informatizados para o alcance do que fora planejado e idealizado pelos participantes. $\mathrm{O}$ diário de campo foi escrito pela pesquisadora logo após o término das oficinas, através do registro e da descrição de todas as ocorrências da oficina. A entrevista semiestruturada foi realizada com os usuários durante a etapa de reflexão, através do levantamento das informações necessárias para o alcance do objetivo da pesquisa.

A análise dos dados foi realizada a partir da triangulação dos dados dos diários de campo, entrevistas, observações e produções postadas no blog a partir das proposições teóricas mencionadas, e teve como foco os objetivos da pesquisa: discutir os efeitos do exercício de autoria em blog e analisar os efeitos da participação nas oficinas e na produção de materiais, na perspectiva dos usuários. As categorias de análise elencadas, a partir dos dados coletados foram:

*aprendizagem na construção do blog: foram elencados os relatos, os extratos de diário de campo e as entrevistas, em que os usuários descreveram seu processo e conteúdo da aprendizagem;
* efeitos da oficina na vida pessoal: foram elencados os relatos, os extratos de diário de campo e as entrevistas em que os usuários trouxeram os efeitos atribuídos à participação na oficina quanto à vida pessoal.

\section{As experiências do exercício de autoria em blog}

A proposta de coletivo foi sendo agenciada durante a construção da oficina. Inicialmente, convidados a criarem um blog, os usuários lançaram questionamentos quanto à sua viabilidade. Nesse momento, demonstraram dúvidas sobre a própria capacidade de autoria e de uso dos equipamentos disponibilizados na oficina. Tal questionamento deveu-se também ao processo de desvalorização socialmente construído e que assola pessoas em sofrimento psíquico. O reconhecimento da capacidade criativa e do uso dos equipamentos digitais foi desenvolvido no decorrer das oficinas, com demonstrações de entusiasmo e de participação ativa com produção de conteúdos para o blog. Podemos pensar que esse efeito está inserido no processo de inclusão digital. Foresti e Teixeira afirmam que a inclusão proporciona o reconhecimento das potencialidades e das responsabilidades dos sujeitos ao se apropriarem das tecnologias de forma criativa e diferenciada, pois isso os liberta de uma posição passiva. Dessa forma, na perspectiva de Venturini et al. (2003), podemos verificar que os usuários do CAPS participantes da oficina de informática se reconheceram como parte de um processo, desempenhando papéis de protagonistas.

\section{Categoria 1: aprendizagem na construção do blog}

Na proposição da proposta de construção do blog e em sua estruturação, foram passados alguns processos, desde os cognitivos (de reconhecimento do blog, suas características e diferenças quanto a outras ferramentas), de 
produção (escolha de servidor, escolha de nome do blog, definição do layout, produção de materiais para postagem) e divulgação e depoimentos quanto às experiências vivenciadas durante esse processo. Nesse processo como um todo, podemos afirmar que vivenciamos algumas vantagens do blog, como as apontadas por Oliveira (2006):

escrita colaborativa partilhando informações de interesse comum, criatividade através da escrita livre promovendo autoria e co-autoria, desenvolvimento de expressão e opinião pessoais, pensamento crítico e capacidade argumentativa, desenvolvimento de habilidades e aprendizagem. Isso favoreceu a autonomia na criação. (Bittencourt \& Francisco, 2011, p. 95)

Tal processo de autonomia foi constituído a partir do já existente, que havia sido ressignificado no acontecer grupal. Um exemplo de tal processo pode ser visto na escolha do nome do blog² do grupo, que foi Criando Laços, sugerido pelos usuários participantes, a partir do título do projeto de extensão. O título é o mesmo do projeto, mas com explicação e design próprios criados pelo grupo na oficina. Houve a decisão por nomes fictícios tais como: Hades, Maria, Adele e Liga dos Campeões.

A apresentação do blog contou com transformações do modelo proposto pelo blogspot, com alteração do seu aspecto estético, estrutural e produção de textos próprios, como discutem Mercado, Mercado,Viana, Pimentel, Rocha e Pinto, (2011). As oficinas permitiram o estabelecimento de laços e de afetividade entre os integrantes, de acordo com Mendonça, e, além disso, refletem os sentidos que foram produzidos nessa relação: vínculo, acolhimento e inclusão, como destacam Brêda (2006) e Oliveira e Fortunato (2007).

Ressalta-se o processo de interação e de criação de laços entre os participantes da oficina na perspectiva da amizade e do efeito que pode ser produzido: transformações em suas próprias vidas. Saraceno (1999), ao tratar da reabilitação psicossocial, descreve que as oportunidades de trocas de afeto constituem um dos caminhos para a criação de um efeito habilitador. Sendo assim, podemos pensar no blog como uma ferramenta interessante para viabilizar a reabilitação psicossocial a partir da inclusão digital e da autoria na produção de conteúdos e de layout. Ainda nessa perspectiva,

O exercício de autoria em blog se constituiu em um espaço para expressão e comunicação no qual os participantes não estavam acostumados a utilizar, promovendo novos modos de vida. Através do blog, os participantes construíram outras relações com eles mesmos, pensaram sobre questões do seu dia a dia gerando reflexão quanto ao que queriam dizer, como iriam dizer, o que utilizar, oportunizando um processo de transformação pessoal e de reabilitação como propõe Saraceno (1999) quando fala da identidade. (Bittencourt \& Francisco, 2011, p. 99)

Além da página coletiva, houve espaço para página pessoal de cada usuário, que pôde criar a sua própria página de acordo com as suas representações e interesses; as produções resultavam do que cada um julgava ser significativo para si próprio.

Assim, o blog possibilitou a criação de um espaço de liberdade de expressão no contexto de pesquisa, como escrevem Nascimento, Silva e Mercado (2008), redundando no que afirmam Ricardo e Vilarinho (2006) existir em blog: um reflexo dos seus autores e do grupo do qual fazem parte. Na oficina, os usuários foram estimulados à criatividade e ao exercício da autonomia, sendo que os materiais para o blog foram produzidos de acordo com os seus próprios interesses. Esse processo de autoria gerou reflexão quanto ao que queriam dizer, como iriam dizer e o que utilizar. 
Em termos de apropriação tecnológica, a produção do blog envolveu a aprendizagem no uso de recursos como: editor de texto, editor de apresentação, editor de imagens, internet. Os usuários desenvolveram habilidades (Neves \& Boeira, 2010) para digitação, uso de site de busca, produção de desenhos e para postagem do conteúdo no blog. Para tanto, a produção oportunizou o acesso e o uso dos computadores, experiência ímpar para alguns usuários, pois esse fora $\mathrm{o}$ único momento de contato e de produção com computadores. Nesse sentido, a oficina possibilitou a inclusão digital como direito, exercício de cidadania e produção (Moro, Teixeira, \& Martins, 2009).

\section{Categoria 2: efeitos da oficina na vida pessoal}

Durante as oficinas, na construção do blog, um dos temas comuns nos relatos dos usuários foram situações das suas vidas, incluindo os problemas cotidianos e as tristezas. O compartilhamento dessas questões dava-se na mesma medida em que se produziam materiais para o blog, podendose afirmar que esse conteúdo transversalizou a produção, dotando-a da circulação dos afetos. Isso favoreceu o interesse da ajuda mútua, contribuindo ainda mais para o fortalecimento dos laços do grupo, dos laços de amizade já abordados.

Quando incitados a comentar sobre a oficina, os usuários afirmaram que se sentiram mais capazes para realizar atividades complexas, como produzir textos reflexivos. No início, disseram que não se sentiam em condições para produzir, por desconhecer blog, internet e outros aplicativos disponíveis nos computadores, mas, com o operar na oficina, sentiram-se reabilitados em suas potencialidades e capacidades. Podemos vislumbrar aqui o potencial da reabilitação psicossocial, tal como descrita por Saraceno(1999) no tocante ao aumento das possibilidades. Além disso, os usuários demonstraram satisfação com a produção que foi postada no blog, tanto das suas quanto dos outros integrantes da oficina. Constatou-se, como enfatizam Jorge et al. (2006), que as atividades ajudaram os sujeitos a dominar as suas limitações e possibilitaram a efetivação de uma das formas para promover a saúde mental.

Depoimentos dos participantes autores do blog:

Feliz por um sonho realizado. O blog representa tudo (HADES);

Para mim é a sensação do dever cumprido, uma conquista. Me senti útil (MARIA); Eu me sinto alegre (LIGA DOS CAMPEÕES); É legal pôr as coisas que você gosta no blog. Fiquei feliz (ADELE).

Hades afirma que as atividades colaboraram para a formação de outra rede de relação, melhor convivência com as pessoas, trabalho em equipe e composição de amizades. Para Hades, o blog representou "tudo em sua vida", sendo um sonho realizado.

Maria apresentava receio no uso do computador, afirmando que em casa o acesso Ihe era negado pela família. Mas, no decorrer das oficinas, foi produzindo arquivos, o que Ihe trouxe confiança em sua capacidade pessoal. Interessou-se em aprender os recursos que mais a atraíam bem como o que necessitaria para as suas produções: adquiriu habilidade para redigir, para navegar na internet e pesquisar. À medida que adquiria habilidade, passou a utilizar os computadores de casa, acesso anteriormente negado. Assim, Maria afirma que o blog representou uma conquista em sua vida.

Liga dos Campeões produzia especialmente assuntos do mundo futebolístico; interessouse pelos recursos do seu interesse e por pesquisas relacionadas ao futebol. Mesmo 
com esse único tema, Liga dos Campeões estabeleceu melhor interação com o grupo e com os demais usuários do CAPS, na medida em que se mobilizou para se expressar nos grupos de reflexão, com significativo progresso na sua comunicação.

Adele utilizou-se dos recursos de que necessitava para realizar as suas produções para o blog. As oficinas contribuíram para a sua interação e comunicação, que se encontravam prejudicadas.

Assim, as oficinas de produção do blog proporcionaram união do grupo, troca de experiências, aprendizagem compartilhada e companheirismo, processo no qual cada participante, com a sua própria história de vida, foi fundamental.

As atividades tiveram a ênfase na invenção de saúde de acordo com o que recomendam Rotelli, Leonardis \& Mauri (2001), promovendo novas possibilidades de produção de vida, sociabilidade e foram direcionadas para o sujeito e suas fragilidades conforme sugerem Oliveira \& Fortunato (2007). Possibilitou-se aos sujeitos o direito de tomarem decisões, de terem suas vontades validadas e suas capacidades criativas em um constante processo de superação. O sofrimento psíquico não se anulou, mas foi possível mudar as formas e o peso desse sofrimento na vida dos sujeitos participantes, de acordo com o que explicam Rotelli, Leonardis \& Mauri (2001). Dessa forma, com consequente valorização para o resgate da sua cidadania e habilitação psicossocial (Bittencourt \& Francisco, 2011).

\section{Considerações finais}

Por meio das oficinas de blog, os usuários puderam conhecer essa ferramenta, formas de manuseio e aprendizagem dos recursos informatizados. O exercício da autoria possibilitou o reconhecimento das suas potencialidades, por eles mesmos, pela família e pelos profissionais da equipe do CAPS. O blog constituiu um espaço de expressão sobre o que era significativo para eles, de autonomia e de demonstração das suas capacidades e potencialidades. As atividades proporcionaram aprendizagem compartilhada, intercâmbio de experiências, socialização, interação, coleguismo, contentamento e fortalecimento dos laços entre os participantes; geraram novos modos de vida, novas relações com os demais integrantes, com eles mesmos e um novo modo de se relacionar com a própria família.

Oportunizar a autoria em blog nesse campo, implantando oficinas tecnológicas nos serviços de atenção ao sofrimento psíquico, proporciona aos sujeitos um relevante ambiente de expressão, comunicação e construção do conhecimento, possibilita produções significativas para a sua vida, reflexões, escrever em nome próprio e falar do seu trajeto. As construções podem ser divulgadas, proporcionando o reconhecimento e a valorização desses sujeitos que são incompreendidos, excluídos e discriminados pela sociedade, e, por isso, elas representam um importante dispositivo para a promoção da saúde mental e, portanto, de reinserção social.

A aprendizagem compartilhada resultante das atividades, os depoimentos quanto ao processo de autoria em blog, o reconhecimento das capacidades e das potencialidades desses sujeitos por parte dos seus familiares e dos profissionais do serviço sintetizam a relevância de oficinas terapêuticas informatizadas e a importância e a necessidade de exploração de outras ferramentas da web quanto as suas contribuições para o campo da saúde mental.

Este estudo poderá contribuir para reflexões quanto à importância da utilização de dispositivos tecnológicos nas oficinas terapêuticas dos serviços de atenção à saúde 
mental, abrindo novas perguntas de pesquisa sobre a relação entre tecnologia e saúde mental e sobre as possibilidades da relação universidade e CAPS; da mesma forma, abre campo para pesquisas futuras na área e no cenário pesquisado. Com a análise dos processos institucionais que ocorrem com a implantação de oficinas informatizadas em CAPS, surgem a perspectiva da equipe sobre habilitação psicossocial e uso de recursos da informática, a perspectiva dos familiares perante os usuários como participantes de oficinas informatizadas e a análise linguística das produções dos usuários, entre outras. 


\section{Ivanise Gomes de Souza Bittencourt}

Mestre em Educação e docente do Curso de Enfermagem da Universidade Federal de Alagoas, Maceió - AL - Brasil. E-mail: ivanisegsb@gmail.com

\section{Deise Juliana Francisco}

Doutora em Informática na Educação e docente do Centro de Educação da Universidade Federal de Alagoas, Maceió - AL - Brasil.

E-mail: deisej@gmail.com

\section{Luís Paulo Leopoldo Mercado}

Doutor em Educação e docente do Centro de Educação da Universidade Federal de Alagoas, Maceió - AL - Brasil.

E-mail: luispaulomercado@gmail.com

Endereço para envio de correspondência:

Rua Vinícius de Morais, 711, Jatiúca. CEP: 57036-330. Maceió, AL.

Recebido 04/06/2012, 1a Reformulação 09/06/2013, Aprovado 29/08/2013. ed.). Rio de Janeiro: Fiocruz.

Arza, E. G. (2011). La implantación de las tecnologías de la información en el ámbito de la salud mental de Bizkaia. Norte de Salud Mental, IX(39), 71-76. Recuperado em 02 julho, 2011, de http://www.ome-aen.org/NORTE/39/71-76.pdf

Bittencourt, I., \& Francisco, D. (2011). O processo de construção de um blog por pessoas em sofrimento psíquico: efeitos do exercício de autoria. Revista EDaPECl, 8(8), 89106. Recuperado em 05 maio, 2013, de http://www.seer. ufs.br/index.php/edapeci/article/view/664/565.

Brasil.(2001). Lei $n^{\circ} 10.216$ de 06 de Abril de 2001. Recuperado em 01 fevereiro, 2011, de http://pfdc.pgr.mpf.gov.br/atuacaoe-conteudos-de-apoio/legislacao/saude/leis/lei_10216_01

Brasil. Conselho Nacional de Saúde. (1996). Resolução no 196 de 10 de outubro de 1996. Recuperado em 17 setembro, 2013, de http://conselho.saude.gov.br/web_comissoes/conep/ aquivos/resolucoes/resolucoes.htm

Brêda, M. (2006). A assistência em saúde mental: os sentidos de uma prática emconstrução. (Tese de Doutorado). Programa de Pós-Graduação de Enfermagem Psiquiátrica da Escola de Enfermagem de Ribeirão Preto da Universidade de São
Paulo, SP. Recuperado em 10 janeiro, 2012, de http://www. teses.usp.br.

Capella, N., Maraschin, C., Maurente, V., \& Rickes, S. M. (2008, jan./jun.). Tecnologias digitais e jovens usuários de serviço de saúde mental. Informática na Educação: Teoria \& Prática, 11 ( 1), 79-90. Recuperado em 20 abril, 2011, de http://seer.ufrgs. br/InfEducTeoriaPratica/article/view/6052/4886

Castells, M. (2000). A sociedade em rede - a era da informação: economia, sociedade e cultura (Vol. 1). São Paulo: Paz e Terra.

Domingues, M. A., \& Paravidini, J. L. (2009). A construção de ofícios terapêuticos em saúde mental. Mental, 7(13), x-x. Recuperado de: http://pepsic.bvsalud.org/scielo. php?script=sci_arttext $\&$ pid $=$ S1679-44272009000200004\&ln $\mathrm{g}=\mathrm{pt} \& \mathrm{nrm}=\mathrm{iso}>$. ISSN 1679-4427.

Foresti, A., \& Teixeira, A. (2006, dez.). As potencialidades de processos de autoria colaborativa na formação escolar dos indivíduos: aprofundando uma faceta do conceito de inclusão digital. Novas Tecnologias CINTED-UFRGS na Educação, 4(2), 1-10. Recuperado em 15 novembro, 2011, de http://www. fluxos.com/aulas/TEXTOSIMGS/COMUNICACAO/Teixeira_ AUTORIA_COLAB_INCLUSAO.pdf

Francisco, D. J. (2007). Criando laços via recursos informatizados: intervenção em saúde mental. (Tese de Doutorado). 


\section{Referências}

Programa de Pós-Graduação em Informática na Educação da Universidade Federal do Rio Grande do Sul. Porto Alegre, RS Recuperado em 5 agosto, 2010, de http://www.lume.ufrgs. br/handle/10183/13256

Guerra, A. M. (2004, jun.). Reabilitação psicossocial no campo da reforma psiquiátrica: uma reflexão sobre $o$ controverso conceito e seus possíveis paradigmas. Revista Latinoamericana de Psicopatologia Fundamental, VII(2), 83-96. Recuperado em 10 janeiro, 2012, de http://www. fundamentalpsychopathology.org/art/jun4/4.pdf

Jorge, M. S., et al. (2006, nov./dez.). Reabilitação psicossocial: visão da equipe de saúde mental. Revista Brasileira de Enfermagem, 15(4), 734-739. doi: http://dx.doi.org/10.1590/ S0104-11692007000400021

Lévy, P. (1993). As tecnologias da inteligência : o futuro do pensamento na era da informática. Rio de Janeiro : Ed. 34.

Marcon, K., Teixeira, A. C., \& Trentin, M. A. (2009). Informática educativa como espaço de inclusão digital: relatos da experiência da rede municipal de ensino de Passo Fundo. In A. C. Teixeira \& K. Marcon (Org.), Inclusão digital: experiências, desafios e perspectivas (pp. 111-130). Passo Fundo, RS: Editora da Universidade de Passo Fundo.

Mendonça, T. C. (2005). As oficinas na saúde mental: relato de uma experiência na internação. Psicologia: Ciência e Profissão, 25(4), 626-235. doi: http://dx.doi.org/10.1590/ S1414-98932005000400011

Mercado L.,Viana, M. A. P., Pimentel, F. S. C., Rocha,M. I, \& Pinto, I. B. (2011). Interfaces da internet na formação docente. Virtual Educa. Recuperado em 24 junho, 2011, de http://www. virtualeduca.info/fveduca/pt/tematica/42-la-universidaden-lasociedad-del-conocimiento-/147-interfaces-da-internet-naformacao-docente.

Michelazzo, P. (2003). Os benefícios da educação e da inclusão digital. In S. A. da Silveira \& J. Cassino (Orgs.), Software livre e inclusão digital. São Paulo: Conrad Editora do Brasil.

Moro, D. M., Teixeira, A. C., \& Martins, A. (2009). Acessibilidade no Kelix: possibilitando a inclusão digital de pessoas com déficit de visão. In A. C. Teixeira \& K. Marcon (Orgs.), Inclusão digital: experiências, desafios e perspectivas (pp. 224-245). Passo Fundo, RS: Editora da Universidade de Passo Fundo.

Nascimento, E. F., Silva, L. R., \& Mercado, L. P. (2008). Uso do blog na prática pedagógica. In L. P. Mercado (Org.), Práticas de formação de professores na educação à distância (pp. 357369). Maceió, AL: Edufal.

Neves, G. V., \& Boeira, A. F. (2010). Blogs como estratégia pedagógica na aprendizagem de estudantes surdos: possibilidades e desafios. In Anais do XV ENDIPE - Encontro Nacional de Didática e Prática de Ensino: convergências e tensões no campo da formação e do trabalho docente: políticas e práticas educacionais. Belo Horizonte, MG.

Oliveira, R. M. (2006). Aprendizagem mediada e avaliada por computador: a inserção dos blogs como interface na educação. In M. Silva \& E. Santos (Org.), Avaliação da aprendizagem em educação online: fundamentos, interfaces e dispositivos, relatos de experiências (pp. 333-346). São Paulo: Loyola.

Oliveira, F. B., \& Fortunato, M. L. (2007). Reabilitação psicossocial na perspectiva da reforma psiquiátrica. Vivência, 32, 155-161.
Recuperado em 07 janeiro, 2012, de http://www.cchla.ufrn.br/ vivencia/sumarios/32/PDF\%20para\%20INTERNET_32/CAP \%2010_FRANCISCA\%20BEZERRA E MARIA\%20LUCINETE.pdf.

Orihuela, J. L. (2007). Blogs e blogosfera: o meio e a comunidade. In Orduña et al. (Orgs.). Blogs: revolucionando os meios de comunicação (pp. 1-20). São Paulo: Thomson Learning.

Ricardo, E. J., \& Vilarinho, L. R. (2006, jun.). A construção da autoria na aprendizagem online: um desafio da pósgraduação. RBPG, 3(5), 59-78. Recuperado em 15 novembro, 2011, de http://www2.capes.gov.br/rbpg/images/stories/ downloads/RBPG/Vol.3_5_jun2006_/Estudos_Artigo1_n5.pdf

Rotelli, F., Leonardis, O., \& Mauri, D. (2001). Desinstitucionalização, uma outra via: a reforma psiquiátrica italiana no contexto da Europa Ocidental e dos "países avançados". In F. Rotelli, O. Leonardis \& D. Mauri (Orgs.), Desinstitucionalização. São Paulo: Hucitec.

Sales, M. V. (2010). Educação a distância e a construção do conhecimento mediada pelas tecnologias: autoria nos processos formativos. In Anais do XV Encontro Nacional de Didática e Prática de ensino - ENDIPE: convergências e tensões no campo da formação e do trabalho docente: políticas e práticas educacionais. Belo Horizonte, MG.

Santarosa, L. M., Conforto, C., \& Basso, L. O. (2010). AVA e ferramentas acessíveis: espaços e autoria coletiva e síncrona para a diversidade humana. In Anais do Congreso Iberoamericano de Informática Educativa. Santiago, Chile. Recuperado em 15 novembro, 2011, de http://www.ie2010. cl/posters/IE2010-156.pdf

Santos, J. E., \& Melo, A. G. (2010). Inserção digital: uma experiência em ambulatório público de saúde mental. Revista Tempus Actas Saúde Coletiva, 4(1), 183-188. Recuperado em 20 abril, 2011, de http://tempus.unb.br/index.php/tempus/ article/viewFile/951/896

Saraceno, B. (1999). Libertando identidades: da reabilitação psicossocial à cidadania possível. Rio de Janeiro: Te Corá.

Sibilia, P. (2002). O homem pós-orgânico. Rio de Janeiro: Relume Dumará.

Souza, L. M., \& Corrêa, E. N. (2008). A autoria do público na mídia digital. In Anais do II encontro da União Latina de Economia Política da Informação, da Comunicação e da Cultura-ULEPICC, (1244-1266). Bauru, SP. Recuperado em 15 novembro, 2011, de http://www2 faac.unesp. br/pesquisa/lecotec/eventos/ulepicc2008/anais/2008 Ulepicc_1244-1266.pdf

Souza, M. I., Silva, L. O., \& Araújo, I. C. (2011, mar.). Autoria na Web 2.0 no contexto da educação e a ética dos hackers. ETD - Educação Temática Digital, 12(Esp.), 154-173. Recuperado em 15 novembro, 2011, de http://www.ssoar.info/ssoar/ files/2011/596/09-marcia\%20e\%20outros_ok.pdf

Teixeira, A. C. (2010). Inclusão digital: novas perspectivas para a informática educativa. ljuí, RS: Ed. Unijuí.

Venturini, E., Galassi, A., Roda, A., \& Sergio, E. (2003). Habilitarse em saúde mental: observações críticas ao conceito de reabilitação. Arquivos Brasileiros de Psicologia, 55(1), 56-63. Recuperado em 10 janeiro, 2012, de http://pepsic.bvsalud. org/pdf/arbp/v55n1/v55n1a07.pdf 